\title{
Development of Students' Discursive-creative Abilities in Foreign Language Learning
}

\author{
P. Labzina \\ Samara State Technical University \\ Samara, Russia \\ labzinapg@mail.ru \\ K. Trubitsin \\ Samara State Technical University \\ Samara, Russia
}

\author{
N. Ageenko \\ Samara State Technical University \\ Samara, Russia
}

\author{
L. Nurtdinova \\ Samara State Technical University \\ Samara, Russia
}

\author{
Yu. Gorbunova \\ Samara State Technical University \\ Samara, Russia
}

\begin{abstract}
Modern engineers' working with professional literature in foreign languages has become an essential part of their job duties. The necessity of dealing with a professional discourse allows marking out special discursive-creative abilities which are a communicative tool of the effective speech interaction. It aims at revealing implicit information of professional importance. In the present study, the authors identify discursive-creative abilities as abilities to arrange the information and to analyze the relations between its elements, to master the implicit knowledge and then to find innovative decisions. The solving of the problem of developing student's discursive-creative abilities specifies an important role of cognitive problems in the process of dealing with scientific discourse encouraging making up personality being ready for the future professional activity. Communicative-cognitive problems answer to this purpose. They are aimed at perception, understanding and creating discourse as the processes mentioned above require such mental operations as analysis, synthesis, comparison, generalization, specification, abstracting in the process of information decoding, deverbalization and explication that result in thinking flexibility, breadth, fluency and originality and lead to its creativity. The theoretical basis allows us to define communicative-cognitive tasks, the purpose of which is to clarify the information in the scientific discourse and to develop professional skills and ways of handling with text data, to express the subject communicative need to influence a partner as the result of problem situation comprehension. It was proved that the use of role play technology is defined by its orientation to the understanding of professional information represented in the scientific discourse, realization of the communicative purpose of the professional intercourse and means of presenting the information in the appropriate form according to the communicative purpose given.
\end{abstract}

Keywords- scientific discourse; implicit; discursive-creative abilities; role play; communicative-cognitive problems

\section{INTRODUCTION}

The educational process in a technical university presupposes students' constant work with scientific discourse, which in turn implies the mastery of knowledge through the processes of understanding and interpretation of information presented explicitly and implicitly [1]. Solving production problems requires a sufficiently high level of awareness of the specialist in specific issues, which becomes possible when addressing and studying professionally relevant information not only in the native language, but also in the foreign language. The development of science and technology is impossible without the exchange of scientific and technical information, which is generalized by the concept of scientific and technical communication. Modern science is international, connected with the spread of ideas through language barriers, i.e. by translation. These factors cause the need to prepare graduates who are able to creatively approach problems through the use of professionally relevant information, which in turn requires constant work with the scientific and technical discourse in the educational process of the university, aimed at developing the ability to explicate the subject-semantic content, decoding and de-balancing in the process of perception, understanding and interpretation of professionally oriented information.

\section{THE NOTION OF SCIENTIFIC AND TECHNICAL DISCOURSE}

The scientific and technical discourse is formed by a complex of all verbal and non-verbal means realized for the exchange of information in the scientific and technical sphere of communication and can be presented either verbally or in writing. The main means of communication in the field of science and technology is precisely the text (written fixed speech), although the exchange of scientific and technical information can also occur through oral speech (for example, 
reports, discussions, debates, reports on scientific and technical issues).

To clarify the concept of "discourse", the authors turned to the study of this notion conducted by E.S. Kubryakova, according to which discourse is such "form of using the language in real time which reflects a certain type of social activity of a person, which is created for the purpose of constructing a special world (image) with the help of its detailed language description and is generally a part of the process of communication between people characterized by participants in communication, conditions of implementation and goals" [2].

In the study of N.D. Arutjunova's concept of "discourse" (from French "discours" - speech), it is treated as a coherent text in conjunction with extralinguistic - pragmatic, sociocultural and other factors; text taken in the event aspect; speech, considered as a purposeful social action, as a component involved in the interaction of people and the mechanisms of their consciousness (cognitive processes). Discourse is "speech immersed in life." Unlike the text, discourse is primarily a model for the realization of certain communicative intentions in the context of a specific communicative situation and in relation to a certain partner, a representative of another culture, expressed by appropriate linguistic and non-linguistic means in this situation. Thus, the concepts of "text" and "discourse" are correlated as a "processproduct", that is, discourse is a text taken in an eventual aspect, socially directed and incorporating extralinguistic factors [3].

As a working definition, let us consider the concept of "discourse" as verbalized speech-activity, realized in a complete speech work, including not only linguistic, but also extralinguistic components [4].

Numerous theories of discourse research allow us to speak about the legitimacy of its pedagogical status.

The necessity of forming the skill of working with scientific and technical discourse as a professionally significant quality of the future graduate is due to its universal application in all spheres of life.

\section{HERMENEUTICAL APPROACH TO THE PROBLEM OF CREATIVE THINKING DEVELOPMENT}

Theoretical analysis and practical experience allow us to assert that the development of creative thinking is based on the development of the skills of understanding and interpreting text as a result of explication, decoding, and deverbalization of information. This idea gives grounds for using the hermeneutic approach in this study.

According to the definition, hermeneutics is the art and the theory of interpretation and the understanding of texts. In turn, understanding is always connected with thinking and is one of its properties, manifested in the productive process of cognition of the new by attracting previously acquired experience. Clarifying the significance of the phenomenon under consideration, it should be noted that to understand an object is to reveal it in all relationships and relations. The empirical experience of foreign and domestic psychologists shows that "understanding" is interpreted as solving problems and cognitive tasks. The confirmation of this idea can be found in the study of V.A. Molyako, according to which the understanding of the problem can be represented in two stages: the understanding of the condition of the task, its requirements and the essence and understanding the result to be found (clarifying its correctness, the adequacy of the task's condition) [5] .

Analysis of the scientific literature allows us to assume that understanding is the comprehension of the object reflected in knowledge: understanding is the formation of the meaning of knowledge in the process of acting with it. In this sense, the three types of mental operations and actions are the most significant: recognition of familiar features in some new material; forecasting, putting forward hypotheses about the past or future of an object that needs to be understood; combining the elements to be understood into the whole. Each type of mental operations plays an important role in the activity of the person solving the problem, which contributes to the generation of the corresponding understanding form of object-understanding-recognition, understanding-hypothesis or understanding-unification $[6,7]$.

The study of V.M. Bukatov is actual for this work as it is devoted to the application of the main provisions of hermeneutics in the pedagogical process. V.M. Bukatov notes that the problems of understanding and inter-understanding to the large extent determine the meaningfulness of any humanitarian discipline teaching. The essence and the mechanism of understanding are interpreted in different ways. However, the common point is that understanding the text, the phenomenon, or the subject is unique and individual, and the correctness of understanding is relative. The understanding of the subject can change quantitatively and qualitatively in the process of acquiring life experience and overcoming the "misunderstanding", which is a natural and inevitable stage of any understanding and in which the individuality and uniqueness of the phenomenon can manifest themselves. "Wrong understanding" should not be stopped, but, on the contrary, its expansion and deepening should be stimulated what results in subject ideas changing [8].

A powerful tool of understanding is language and speech, the logical and precise organization of which leads to an understanding of the goal being achievable in the process of communication. The cognitive task must acquire the correct verbal expression, which determines the direction of the recipient's mental activity to create an appropriate image of this task, to move from it to a rule, a concept, etc.

It was determined that the success of understanding depends not only on the knowledge of the person, but also on the motives that lead to cognitive activity, the main ones being the needs of the individual, his interests, curiosity, sense of responsibility, awareness of the need to acquire knowledge thoroughly from different disciplines [9].

In the context of the hermeneutic approach used as the methodological basis of this research, attention should be paid to the connection between understanding and interpretation. According to the prevailing traditions of hermeneutics, interpretation is viewed as a way to search and highlight 
meanings in the object of understanding in the entire wealth of the individual-personal context [10]. That sense, singled out and deciphered by the interpreter (recipient), is the basis of his understanding, in the process of which a subjective interpretation is given to the idea to be understood by the individual seeks. The idea mentioned above allows us to conclude that understanding is the revealing of the author's ideas and thoughts, and the interpretation is the finding the reader's own meaning. To prove the close connection between the processes of understanding and interpretation, L.M. Vekker claims that understanding itself is a condition for the emergence of possible interpretations, but at the same time the breadth of the interpretation of the object not only qualitatively but also quantitatively characterizes the degree of its understanding. The conclusion is that the main task of interpretation is to isolate from the set of possible variants conditioned by the context, that sense, which corresponds to the cognitive needs of the interpreter, actualized in the process of perceiving the text information. With the support of the above-mentioned statements, it should be noted that the interpretation of the subject is a form of understanding associated with the way of the individual thinking. Such view of the role of interpretation in the structure of mental processes allows the recipient of information to be viewed not as a passive object of discourse but as a subject influencing actively the outcome of this impact.

Thus, the theoretical analysis of the problem of information understanding and interpreting in the course of working with discourse as the main categories of hermeneutics allowed us to reach a deeper understanding of the hermeneutic approach, its principles and the rules that follow from them, which ensure the effectiveness of the process of developing creative thinking.

The main idea of the hermeneutical approach is the movement of the interpreter on the so-called "hermeneutic circle", which is defined by theorists of hermeneutics in different ways. The most outstanding idea of the hermeneutic circle is associated with the dialectics of the part and the whole: in which case will an adequate understanding be achieved - in the comprehension of the individual parts, of which the whole is composed, or in the comprehension of the whole, which then provides the understanding of the individual parts? The answer to this question allows us to formulate the approach to the hermeneutic circle, which provides the basis for the method of hermeneutic analysis. First it is a general idea of the meaning of the whole (but vague and unclear), then it is a movement from one part to another in order to clarify this view, and finally, correction of the initial understanding.

The hermeneutical approach presupposes the researcher's autonomy at this stage. This independence is connected with the most important position of hermeneutics - the direction of the process of interpretation for personal understanding.

It is revealed that the hermeneutical approach intensifies cognitive activity by activating intuition, imagination and associative connections, correlating with personal needs and values, providing an opportunity for the development of cognitive and motivational components of creative thinking, and also contributes to the formation of a creative environment through educational material that serves as the basis for creating by a student his own educational content in the form of his personal products of creative activity.

\section{DISCURSIVE-CREATIVE ABILITIES}

It is necessary to identify special creative abilities actualizing the process of becoming a student of a technical college. According to M.M. Zinovkina, creative abilities are a set of individual characteristics of a person, determining the possibility of carrying out creative activity and achieving its effectiveness [11]. The research deals with discursive and creative abilities, which are an integrative formation ensuring effective speech interaction, as it acts as a communicativespeech mechanism of its organization, taking into account the nature of communication, extralinguistic and linguistic components, and is aimed at emphasizing implicitly represented (contextual) professionally relevant information.

Discursive-creative ability is defined as an ability to creatively seek innovative solutions; to analyse relations and relations between information elements; to evaluate and structure the information; to identify and develop explicitly (explicit, verbal) and implicitly (subtext) professionally relevant information [12].

The use of discursive-creative abilities in all areas of the student's life determines the pedagogical possibilities of their development. Their feature (setting goals, planning, determining the optimal ratio of goals and means, etc.) contributes to the development of reflection at the level of habitual inner action, which is extremely necessary for the future of a bachelor of any profile, and is an indicator of a mature personality with a high level of consciousness and professional self-awareness. In this context, discursive and creative abilities are an important element of general cultural and professional competencies, which represent a unity of theoretical and practical readiness and ability of students to carry out educational activities, readiness and ability to learn all their lives.

According to the Federal State Educational Standard of Higher Professional Education of the Third Generation [13], the bachelor must have a culture of thinking, be capable of generalizing, analyzing, perceiving information, being able to logically, reasonably and clearly construct an oral and written speech, be ready to cooperate with colleagues, work in a team, be able to understand the essence and significance of information in the development of the modern information society, to use information in global computer networks, to have the skills of public and scientific speech and the ability to create and edit professional texts, to be able to use normative legal documents in their activities, have the ability to review and analyse various technical documentation. These general cultural competencies emphasize that under the conditions of scientific and technological progress, the practical acquisition by the technical school student of the skills and skills of working with scientific and technical discourse acquires special significance and is an integral organic component of the modern training of specialists. 
The research showed that the ability to adequately perceive, comprehend and understand the information received is one of the shortcomings in mass education, so the key task of modern education is to teach students to understand a text presented and to create their own, relevant pragmatic situation. Textual information skills - the receptive component of communicative competence - are of general interest and are of a universal nature [14]. Thus let us consider relevant to use communicative and cognitive tasks in the learning process to develop the student creative thinking at a technical university.

\section{COGNITIVE TASKS IN COMMUNICATION}

Theoretical analysis of the researches in this field makes it possible to distinguish such communicative and cognitive tasks of the speaker as a message, conviction, prompting, a suggestion, an approval, explanation, a refutation, a proof, a question, etc., and of the listener - to understand, to remember, to make a conclusion, to refute, to prove.

According to S.A. Shapoval, a communicative and cognitive task, aimed at explication, understanding and interpretation of information of scientific and technical discourse, is defined as "a psychologized form of presentation of the results of professional understanding, focused on the reproduction of the mechanism of understanding the text in learning conditions [15]. These tasks are communicative because they are aimed at achieving understanding as a result of their decision. These include the following mandatory components:

1) instruction-task, providing a communicative speech situation with a system of specific interacting factors;

2) professionally oriented text that meets the conditions of the situation and allows one to carry out speech action and achieve the planned goal-result;

3) control of performance, providing for the output with the product of speech activity in communication of written or oral form.

Thus, the above-mentioned theoretical propositions lead to a conclusion that the communicative cognitive task is the expression of the goal that must be achieved by searching, accepting and implementing the semantic verbal solution in the process of perception, understanding and interpretation of professionally oriented discourse.

\section{CREATIVE TEACHING TECHNIQUES}

One of the obstacles to the development of creative thinking of a technical university student in the process of working with a foreign scientific and technical discourse is the passivity of the trainee. So, there is a need to create a positive motivation for the student to learn a foreign language with the help of various educational technologies. One of them was a role-playing game, representing the conditional reproduction by its participants of the real practical activities of people and the conditions of real communication [16]. The effectiveness of training was due primarily to increased motivation and interest in the subject. In addition, knowledge, the mastery of which was the educational goal of the game, was seen as a means to achieve a specific game goal and was of an applied nature - the game made students look at knowledge as something that can bring real benefits. The attention was paid to the principle of subjectivity of the trainee, i.e. the student was an active participant - a subject of his own education, who mastered not only knowledge, but also the ways of obtaining them [17]. Role-playing games made it possible to introduce unpredictable moments that contributed to the development of a creative approach to solving communicative cognitive tasks.

Considering the noted advantages of role-playing games as educational creative-hermeneutic technologies, the authors used their potential in the development of the discoursecreative abilities of a student at a technical university. In situational and content aspects, the authors' role-playing games were brought closer to the topic "Translation Activity" and "Nanotechnology". Students were asked to play situations such as "Translation Bureau", "Is Google a Friend or an Enemy of an Interpreter?", "Teacher and Students' Position in Translation Studies", "Translation at a Scientific Conference", "Business Visit to London", "False Friends of an Interpreter", "Entertaining nanotechnology for children"', etc. The increased interest of students in conducting classes in the form of role-playing game should be noted. According to their opinion, they felt that they are "masters of the situation", able to turn the course of action in the direction necessary for them and solve the arising problems easily. Such attitude relieved tension and helped to reveal the creative potential of students.

Role-play allowed one to realize the subject-subject interaction in the process of setting and solving communicative and cognitive tasks. The tasks included such components as instruction-task, providing a communicative speech situation with a system of specific interacting factors; a professionally-oriented text, allowing one to carry out speech action and achieve the planned goal-result; control of performance, providing for the output with the product of speech activity in communication of an oral or written type $[18,19]$. For example, one of the communicative and cognitive tasks of the role-playing game "Nanotechnology for Children" consisted of the following formulation: "Prepare a message and a presentation on nanotechnology for addressing children's audience at the exhibition of the latest scientific and technological achievements." At the first stage of the solution, the analysis of the composition of the task was carried out, support concepts were identified that facilitated understanding of actions to achieve the goal: communication, presentation, nanotechnology, and the children's audience. Then there was an actualization and organization of knowledge about each of the selected categories in order to determine those means (verbal, visual) that will ensure the effectiveness of the result obtained. At the next stage, students tried to recode (reformulate) the problem for a more detailed understanding of its condition [20]. For example, "Taking into account the peculiarities of the children's audience, prepare a message ...", "Make Nanotechnology accessible to children", "Engage children in a colorful presentation about the microcosm". At the stage of solving the communicative and cognitive task, lexical and grammatical means were selected for communication on the topic of nanotechnology, corresponding to the pragmatic aspect of the situation, that is, the focus on 
the children's audience; making presentations with the help of the computer program Power Point on the basis of understandable and accessible to children images that served as a base for memorizing new information. A retrospective analysis of the solution of the problem was carried out by the remaining students of the group who represented the children's audience. They concluded that the presented solutions to the problem met the goal.

Teamwork during the development of the scenario roleplaying game contributed to mutual support and support of all participants. For example, students who did not have a need for cognitive activity during the experimental work, however, showed independence in the search for background information to solve the task, which actualized the expansion of their horizons and formed personal responsibility for the result of the work [21, 22]. Students who have no profound knowledge of the mechanisms for solving cognitive tasks in the aspect of working with a foreign scientific and technical discourse succeeded in combining and transforming the previously learned knowledge to solve new problems, sometimes improvising, which indicated the absence of anxiety and tension in the educational process. The students, using information received from the text creatively, it was typical to display ingenuity, developed imagination, individual style in the approach to solving cognitive tasks, in organizing collective activities, had the ability to look at a given situation from the side and give adequate assessment.

\section{CONCLUSION}

The result of using creative teaching techniques aimed to develop discourse-creative abilities in the educational process has become motivation for the development of cognitive activity. It allowed one to aware the importance and application of information obtained earlier in different contexts, to develop creative discursive abilities that determine analysis, decision-making, interaction, communication, selfdevelopment through other participants in the role-playing game, interrelation of scientific and professional activities.

\section{References}

[1] L.M. Vekker, Mind and reality: a uniform theory of mental processes. Moscow: Smysl, 1998, 685p.

[2] E. S. Kubryakova, Language and knowledge: On the way of getting knowledge about languages: Parts of speech from cognitive point of view. The role of language in the world cognition. Moscow: Yazyki slavyanskoj kul'tury, 2004, 560 p.

[3] N.D. Arutjunova, Sentence and its meaning. Logic and semantic problems. Moscow: Editorial URSS, 2003, 383 p.

[4] A.A. Samorukov, Students' discoursive competence forming in the educational process of high school: abstract of thesis cand.of ped. sci. Orenburg, 25, 2008.
[5] V.A. Molyako, Psychology of design activity. Moscow, 1983. 69p.

[6] M.R. Kudaev, M.B. Bogus, M.K. Kyatova, "The system of educational and cognitive tasks in the study of a humanitarian subject," West. Adyghe University, No. 1, pp. 167-169, 2006.

[7] C. C. Navarrete, "Creative thinking in digital game design and development," A case study Computers \& Education, vol. 69, pp. 320-331, November 2013.

[8] V.M. Bukatov, "Pedagogical Sacraments of Didactic Games", 2 nd ed., Rev. and additional, Moscow: Moscow. Psychological and social. Institution: Flint, 2003. 153p.

[9] R.V. Pavlenko, Psychology [electronic resource], Access mode: World Wide Web. URL: http://www.uchebnikionline.ru.

[10] F. Lebech, "The concept of the subject in the philosophical hermeneutics of Hans-GeorgGadamer," International Journal of Philosophical Studies, No.14 (2), pp. 221-236, 2006.

[11] M.M. Zinovkina, NFTM-TRIZ: creative education in 21 century, Moscow, 2007, 310p.

[12] P.G., Labzina, A.V. Moskvina, Creative potential of a cognitive task in students creative thinking development. Orenburg: GBU RTSRO, 2014,pp. 55-57.

[13] Coordination board of academic and scientific councils of high school. Available at:http://www.fgosvo.ru/fgosvpo/7/6/1. Accessed March 15, 2017.

[14] Net research laboratories "School for everybody" Available at: http://www.setilab.ru. Accessed March 7, 2017

[15] S.A. Shapoval, Task approach in teaching to understand texts. Moscow: Staryj Oskol, 2007,131p.

[16] V.P. Bespalko, Pedagogy and advanced teaching technologies, Moscow: Pedagogika, 1995, $336 \mathrm{p}$.

[17] Jung-Ho Jung , Don-Ryun Chang "Types of creativity-Fostering multiple intelligences in design convergence talents," Thinking Skills and Creativity, vol. 23, pp. 101-111, March 2017.

[18] S.Kaycheng, "Fostering student creativity through teacher behaviors," Thinking Skills and Creativity,vol.23, pp. 58-66, March 2017.

[19] O.O. Oskay, "Prospective teachers' creativity-fostering behaviors: Perceptions on their technology skills and success in project based material development," Problems of Education in the 21st Century, vol. 63, pp. 84-92, 2015.

[20] N.V. Ageenko, D.D. Dorofeeva "Innovative Technologies in the Educational Process: Trends, Prospects of Development," Vestnik of Samara State Technical University, Psychological and Pedagogical Sciences Series,No. 2 (34), 2017, p. 6.

[21] P.G. Labzina, , A.V. Moskvina, "The Creative translation of the scientific text in the process of foreign language learning," Vestnik of Samara State Technical University, Psychological and Pedagogical Sciences Series, No. 3 (23), 2014, p. 104.

[22] P. Almeida, J.J. Teixeira-Dias, J. Medina Building a Culture of Creativity while Engaging Science Students in Inquiry C. Holtham, C. Nygaard, N. Courtney (Eds.), Teaching Creativity Creativity in Teaching., Libri Publishing, Oxfordshire, 2010. 